\title{
SECAGEM DE HORTELÃ EM SECADOR DE CESTO ROTATIVO
}

\author{
A. H. ROSANOVA ${ }^{1}$ e M. C. FERREIRA ${ }^{1}$ \\ ${ }^{1}$ Universidade Federal de São Carlos, Departamento de Engenharia Química \\ E-mail para contato: mariaf@ufscar.br
}

\begin{abstract}
RESUMO- O objetivo desse trabalho foi avaliar a secagem de hortelã em um secador desenvolvido para esse fim, visando à obtenção de um produto desidratado homogêneo e adequado para a comercialização. $O$ secador consiste de um cesto metálico cilíndrico com paredes perfuradas, acoplado a um motor, que lhe confere movimento rotacional em torno do eixo horizontal. $\mathrm{O}$ ar é aquecido por uma resistência elétrica, e é alimentado através das paredes laterais perfuradas, perpendicularmente ao eixo de rotação. Na secagem foram utilizadas duas temperaturas do ar $(70$ e 80 oC) e avaliadas a redução de umidade, alteração de cor e da densidade bulk da hortelã durante o processo. A secagem foi uniforme, sendo que a redução da umidade do material variou pouco entre as duas temperaturas testadas, e a umidade final das hastes foi, em média, inferior à das folhas. Já a variação da cor foi menor para os ensaios a 70 oC. Foi observado um expressivo encolhimento do material durante a secagem, nas duas temperaturas.
\end{abstract}

\section{INTRODUÇÃO}

Após serem colhidas, as plantas iniciam um processo irreversível de degradação, devendo ser imediatamente comercializadas, consumidas ou desidratadas, visando à minimização das perdas de qualidade e no teor dos seus princípios ativos. A secagem é um dos métodos mais convenientes para a preservação de plantas, visto que além de reduzir o desperdício, ela facilita o seu manuseio, transporte e armazenagem (Dias et al., 2011; Ribeiro e Diniz, 2008; Sangwan et al., 2012).

Dentre as espécies de plantas conhecidas, a hortelã, que é o foco deste trabalho, é uma das mais utilizadas. Seu óleo essencial pode ser empregado na indústria farmacêutica, para a produção de cosméticos e medicamentos, e tanto o óleo quanto a planta seca têm usos na indústria alimentícia, na fabricação de condimentos, chás, etc. (Dias et al., 2011; Sangwan et al., 2012). O ramo de hortelã é constituído de folhas e hastes, que são materiais com características distintas em termos físicos (forma, dimensões, etc) e químicos (composição, teor de constituintes, etc.). Segundo Tarhan et al. (2010), a hortelã in-natura possui, tipicamente, umidade de $75-85 \%$ (bu), sendo que a umidade das folhas é ligeiramente menor que a das hastes. As diferenças entre folhas e hastes se torna um complicador para o processo de secagem quando se deseja secar a planta inteira, já que por possuírem características distintas, estes materiais apresentam cinéticas de secagem diferentes. Nesse sentido, Tarhan et al. (2010) observaram que as folhas perdem umidade mais rapidamente que as hastes.

No caso de plantas, a secagem pode comprometer a qualidade do produto final, visto que materiais biológicos são muito sensíveis à temperatura, que pode provocar a degradação de 


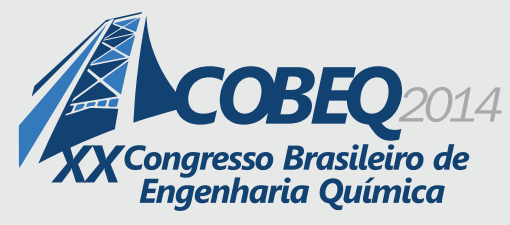

19 a 22 de outubro de 2014

Florianópolis/SC

componentes químicos e alterações de odor, cor e sabor, o que afeta a aparência e qualidade do produto e, portanto, influencia a escolha do consumidor (Ribeiro e Diniz, 2008). Uma vez que cada espécie de planta medicinal possui características particulares, Melo et al. (2004) evidenciaram a necessidade de realizar estudos que estabeleçam as melhores condições de operação para a secagem de cada espécie, em um tipo específico de secador.

$\mathrm{Na}$ literatura existe uma vasta gama de trabalhos onde a secagem de plantas medicinais foi avaliada, utilizando-se diferentes tipos e dimensões de secadores e condições de processo. É comum o uso de secadores de leito fixo, como secadores de bandejas e estufa (Blanco et al., 2000; Dias et al., 2011; Radünz et al., 2006). Lima (2013) observou que a utilização de leitos fixos para a secagem de plantas pode resultar em um produto final não uniforme. Assim sendo, a autora sugeriu a utilização de secadores de leitos móveis, que possibilitem boa movimentação do material e bom contato entre os sólidos e o ar de secagem, tais quais os secadores do tipo tambor rotativo. Alguns testes de secagem de hortelã-comum em um secador rotativo convencional foram realizados previamente a este trabalho. Contudo, a presença de hastes e folhas, e as características do material dificultaram a sua movimentação no secador, e os resultados não foram satisfatórios. Além disto, foi observado um considerável encolhimento e murchamento durante a secagem, o que piorava a movimentação. Com base nestes testes, foi construído um protótipo de um novo secador, denominado cesto rotativo, visando à aplicação na secagem de folhas e hastes de hortelã.

Os objetivos do presente trabalho foram avaliar o desempenho do secador tipo cesto rotativo para redução de umidade de hortelã em diferentes temperaturas, e também avaliar as alterações nas propriedades do material (cor e densidade bulk) em função do tempo, durante a secagem. A variação da cor é considerado um atributo de qualidade e possibilita uma análise comparativa do produto seco nas diferentes condições, e a densidade bulk, uma avaliação das alterações associadas ao encolhimento do material.

\section{MATERIAIS E MÉTODOS}

Os ensaios foram realizados no Centro de Secagem do DEQ-UFSCar. Foram utilizadas folhas e hastes in-natura de hortelã-comum da espécie Mentha $x$ villosa Huds, adquiridas em um estabelecimento comercial da cidade de São Carlos-SP. Foi feita uma seleção prévia, procurando-se obter amostras de coloração e tamanhos semelhantes, visando à redução da variabilidade inerente a esse tipo de material. Foram avaliadas duas temperaturas do ar de secagem, $70{ }^{\circ} \mathrm{C}$ e $80{ }^{\circ} \mathrm{C}$, e os ensaios foram feitos em duplicata. Para uma primeira avaliação, optou-se por variar apenas a temperatura, pois de acordo com a literatura, ela é o fator de maior relevância para a cinética de secagem e qualidade do produto.

O sistema experimental utilizado foi desenvolvido com base no princípio de funcionamento dos secadores do tipo tambor rotativo convencionais (Tarhan et al., 2010). O secador construído diferiu dos secadores rotativos pela ausência de suspensores internos, e pela alimentação do ar que é feita através da parede perfurada do cesto, na direção perpendicular ao eixo horizontal. Um esquema e uma foto do secador tipo cesto rotativo são apresentados nas Figuras 1a e 1b. 

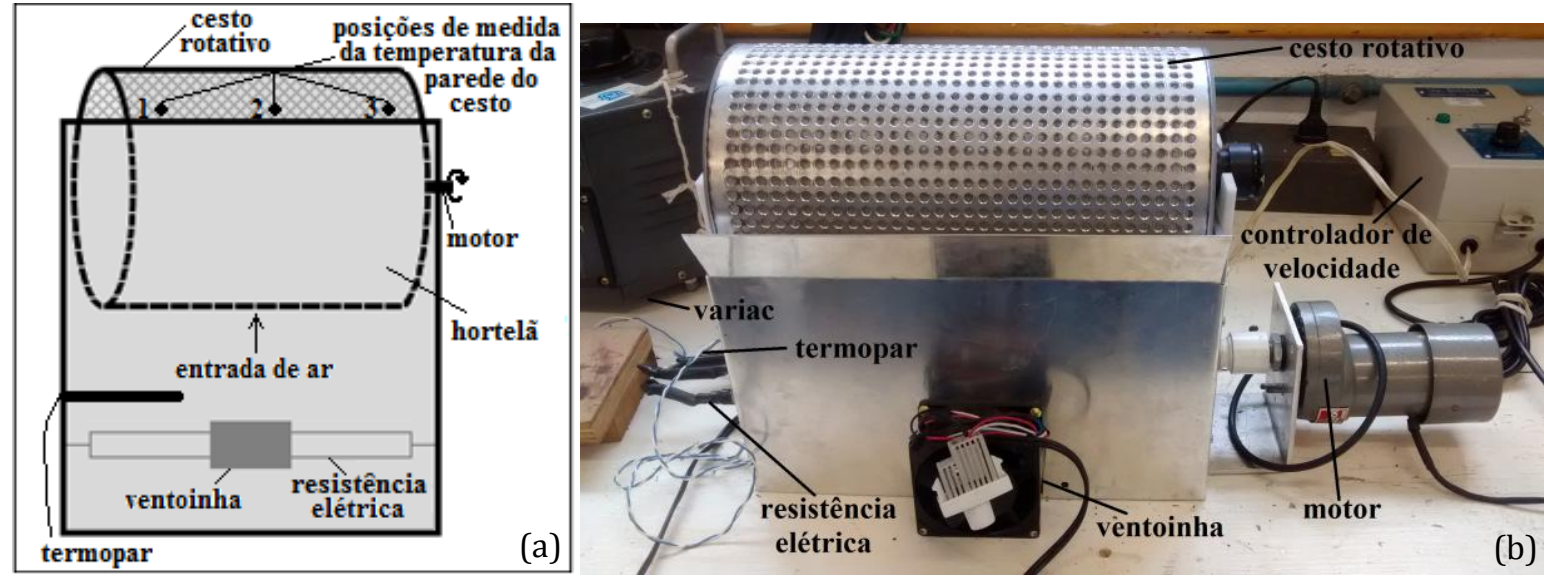

Figura 1 - Esquema (a) e foto (b) do secador do tipo cesto rotativo.

O cesto, no qual é inserido o material a ser seco, possui $26 \mathrm{~cm}$ de comprimento e 14,5 $\mathrm{cm}$ de diâmetro, e foi construído em material metálico perfurado, e revestido internamente com uma tela, que permite a passagem de ar. $\mathrm{O}$ cesto foi acoplado a um motor, o qual lhe conferiu o movimento rotacional, e sua velocidade de rotação foi controlada utilizando-se um controlador da marca Diact modelo 00/510. Uma ventoinha de baixa potência foi acoplada à parede lateral da base de suporte do cesto, para a alimentação do ar de secagem. Uma resistência elétrica foi inserida próxima à ventoinha, para aquecer esse ar. Um Variac modelo M-2412 da marca Auje foi ligado à resistência, e, através do ajuste da potência dissipada, a temperatura do ar de secagem era fixada no valor desejado.

Para a determinação das temperaturas do ambiente e do ar de secagem, foi utilizado um termopar tipo $\mathrm{J}$ da marca Cole Parmer. A temperatura do ar foi medida antes da entrada no cesto, na posição indicada nas Figuras 1a e 1b. Para as medidas de temperatura da parede do cesto e do material durante o processo, foi utilizado um termômetro digital infravermelho modelo MT-350 da marca Minipa. A temperatura da parede do cesto foi medida em 3 posições axiais, que estão indicadas na Figura 1a. A temperatura do material foi medida em 3 posições no interior do cesto, as mesmas utilizadas para as medidas na parede, visando avaliar a homogeneidade da condição de secagem no secador. Um kit tri-sense modelo 37000-95 e uma sonda modelo 37000-61 da Cole Parmer foram utilizados para medir a velocidade do ar no interior do cesto. A sonda foi inserida no eixo central do cesto, e as medidas realizadas de uma extremidade a outra, a cada 2,5 cm do seu comprimento.

Após a seleção inicial, os ramos de hortelã foram cortados em pedaços de 2 a $3 \mathrm{~cm}$ para serem secos. Em todos os ensaios, utilizou-se 240,0 $\pm 0,1 \mathrm{~g}$ de material. Essa quantidade foi definida com base na capacidade máxima do cesto, de modo que ele ficasse cheio sem que o material fosse compactado. A cor, teor de umidade e densidade bulk da hortelã, e as temperaturas do ar, do material e da parede do cesto, foram determinadas no instante inicial, a cada 3 horas, e no fim da secagem. A cor foi determinada para amostras de folhas, de hastes, e de folhas com hastes. A umidade foi medida para cada uma das frações apenas no início e no fim do processo, e durante a secagem a medida foi realizada apenas para folhas com hastes, devido à limitação da quantidade de material disponível. A densidade bulk, em todos os instantes de tempo, foi medida somente para amostras de folhas com hastes. As metodologias usadas para medidas de umidade, cor e densidade bulk são descritas a seguir. 
- Cor: foi medida utilizando-se um espectrofotômetro modelo CM-5 da marca Konica Minolta, e os resultados foram expressos em função dos parâmetros $\mathrm{L}^{*}, \mathrm{a}^{*}$ e $\mathrm{b}^{*}$ do sistema de cores CIELAB. Para o cálculo da variação da cor $\left(\Delta \mathrm{E}^{*}\right)$ foi utilizada a Equação 1. Essa análise foi feita em triplicata;

$$
\Delta E^{*}=\sqrt{\left(L_{\text {inicial }}^{*}-L_{\text {final }}^{*}\right)^{2}+\left(a_{\text {inicial }}^{*}-a_{\text {final }}^{*}\right)^{2}+\left(b_{\text {inicial }}^{*}-b_{\text {final }}^{*}\right)^{2}}
$$

- Teor de umidade: foi determinado utilizando uma termobalança modelo IR-200 da marca Denver Instrument. Para o cálculo da umidade adimensional (MR), a equação 2 foi utilizada:

$$
M R=\frac{X-X_{e q}}{X_{0}-X_{e q}}
$$

onde $\mathrm{X}, \mathrm{X}_{0}$ e $\mathrm{X}_{\mathrm{eq}}$ são as umidades, em base seca, no instante t, inicial e de equilíbrio, respectivamente;

- Densidade bulk $\left(\rho_{\mathrm{b}}\right)$ : uma amostra de folhas com hastes foi inserida em uma proveta, e o volume ocupado pelo leito de material foi determinado. Então, o valor de $\rho_{b}$ foi calculado pela razão entre a massa de amostra e o volume ocupado.

\section{RESULTADOS E DISCUSSÕES}

Os dados de umidade adimensional (MR) em função do tempo para a secagem de folhas e hastes de hortelã são mostrados na Figura 2. A Figura 2a mostra os dados obtidos na secagem a $70{ }^{\circ} \mathrm{C}$ (ensaio e réplica), e a Figura $2 \mathrm{~b}$ os dados comparativos para as temperaturas de 70 e $80{ }^{\circ} \mathrm{C}$.
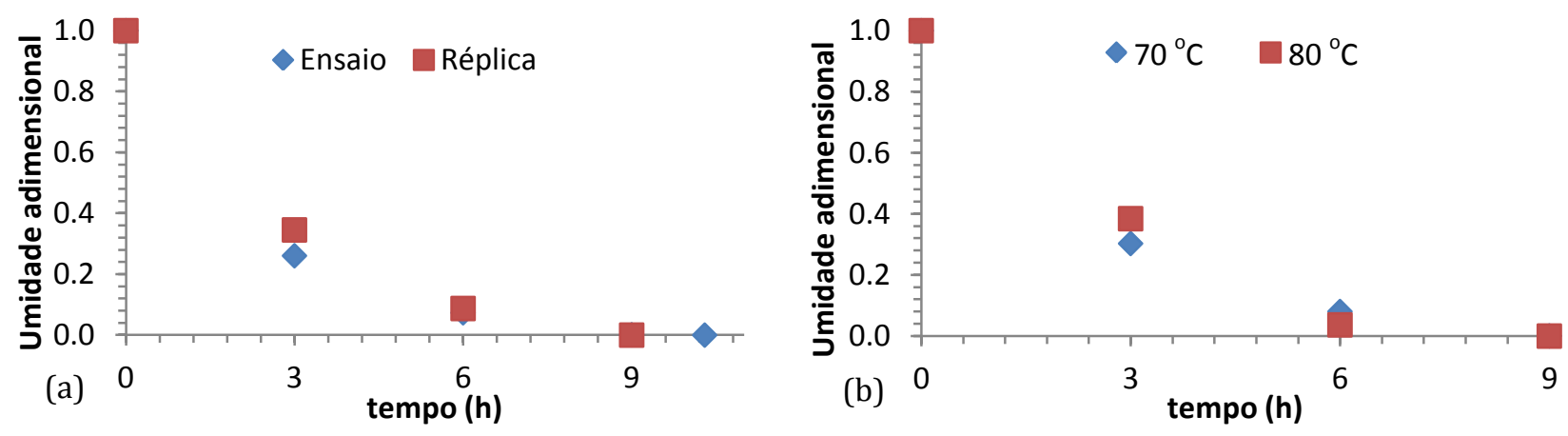

Figura 2 - Umidade adimensional em função do tempo na secagem de folhas e hastes de hortelã; ensaio e réplica a $70{ }^{\circ} \mathrm{C}(\mathrm{a})$; ensaios a 70 e $80{ }^{\circ} \mathrm{C}(\mathrm{b})$.

Para os experimentos realizados a $70^{\circ} \mathrm{C}$ (Figura 2a), é possível notar que os dados obtidos para ensaio e réplica foram próximos, com diferenças inferiores a 16,1\%. Tendo em vista que fatores como a variabilidade inerente à materiais biológicos e a dificuldade de seleção de amostras idênticas para a realização dos ensaios podem dificultar a reprodutibilidade, pode-se considerar que houve uma boa reprodutibilidade entre os ensaios realizados a $70{ }^{\circ} \mathrm{C}$, e para os experimentos realizados a $80{ }^{\circ} \mathrm{C}$ foi observado um comportamento similar. Assim, nas análises posteriores serão apresentados apenas os valores médios dos ensaios realizados em cada temperatura. 


\section{9 a 22 de outubro de 2014 \\ Florianópolis/SC}

Com exceção de um ensaio a $70{ }^{\circ} \mathrm{C}$, em que a secagem foi interrompida após $10,3 \mathrm{~h}$ de processo, todos os demais foram interrompidos após $9 \mathrm{~h}$ de operação. Os ensaios nas duas temperaturas foram efetuados mantendo-se a mesma velocidade do ar. Não foi possível medir a velocidade de escoamento do ar no interior do cesto, uma vez que os valores eram muito baixos para serem registrados pela sonda de medida (cujo limite inferior era de $0,51 \mathrm{~m} / \mathrm{s}$ ). Na Figura $2 \mathrm{~b}$, nota-se que para as duas temperaturas avaliadas, os dados de umidade adimensional em função do tempo não apresentaram diferenças expressivas, o que evidencia que não houve um efeito significativo da temperatura na secagem da hortelã. Isso pode ter ocorrido porque a diferença entre as temperaturas absolutas utilizadas é de apenas 3\%. Além disto, uma vez que parte da energia do ar é dissipada para aquecer as paredes do equipamento e em perdas para o ambiente, nem toda ela é usada efetivamente para a secagem. Embora as perdas ocorram nas duas temperaturas e variem em função da temperatura ambiente, elas tendem a ser maiores quando a temperatura do ar é mais alta, já que a temperatura ambiente não sofreu grande variação entre os ensaios (variou entre 24,2 e $27,5^{\circ} \mathrm{C}$ ).

A pequena diferença entre as temperaturas do material no interior do cesto, nas duas condições avaliadas, pode ser observada nas Figuras $3 a$ e 3b, que mostram a variação desta e da temperatura da parede do cesto em função do tempo (as temperaturas são as médias entre ensaios e réplicas). Observou-se que os valores absolutos da temperatura do material para os ensaios realizados com ar a $80{ }^{\circ} \mathrm{C}$ foram superiores aos com ar a $70{ }^{\circ} \mathrm{C}$ em no máximo $2,6 \%$. Quanto à parede do cesto, as temperaturas absolutas foram até $2,7 \%$ maiores no aquecimento a $80{ }^{\circ} \mathrm{C}$. Esses resultados indicam que as condições no interior do cesto foram semelhantes em todos os ensaios, o que corrobora os dados de umidade adimensional próximos obtidos para os ensaios realizados nas duas temperaturas avaliadas.
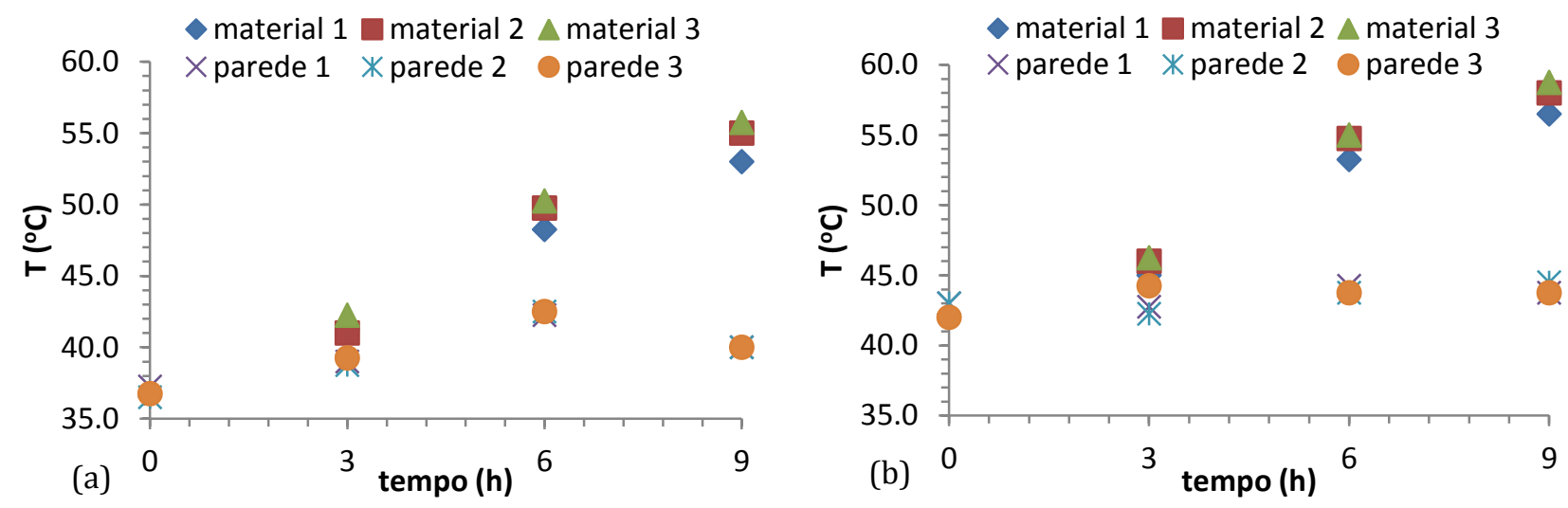

Figura 3 - Temperaturas do material e parede do cesto para os ensaios a $70{ }^{\circ} \mathrm{C}$ (a) e $80{ }^{\circ} \mathrm{C}$ (b).

Ao se comparar as temperaturas do material e da parede nas diferentes posições de medida (1, 2 e 3), nota-se que houve pouca variação entre as temperaturas em todos os instantes de tempo. A máxima variação entre as posições foi inferior a $0,9 \%$, podendo-se inferir que a condição de secagem no interior do cesto foi uniforme durante todo o processo. Visualmente, observou-se que o cesto proporcionou uma boa movimentação do material em seu interior, e que o produto final seco aparentava homogeneidade, tanto para as hastes como para as folhas.

As umidades (bs) de hastes e de folhas do produto seco são mostradas na Figura 4. Observa-se 
que na temperatura de $70{ }^{\circ} \mathrm{C}$, as umidades referem-se a diferentes tempos de secagem, já que um dos ensaios foi interrompido após 9 h e o outro após 10,3 h.

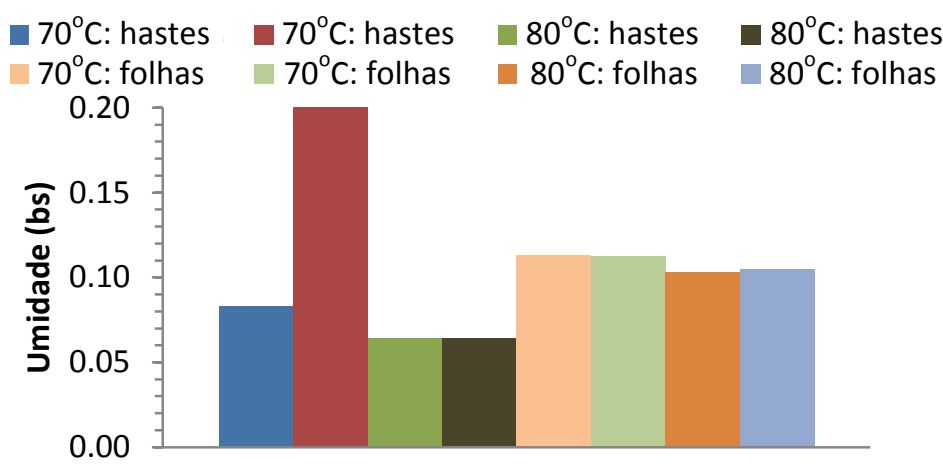

Figura 4 - Umidade final (bs) das folhas ou hastes dos produtos secos dos 4 ensaios.

Conforme pode ser visto na Figura 4, com exceção do ensaio a $70{ }^{\circ} \mathrm{C}$ com 9 h de duração em que a umidade das hastes foi mais alta, nos demais a umidade final das hastes foi sempre menor que a das folhas. Este resultado não concorda com o relatado por Tarhan et al. (2010), que obtiveram umidades finais maiores para hastes em relação às folhas na secagem da hortelã-pimenta em secador rotativo. Esta discrepância ainda precisa ser melhor investigada, mas ela pode estar associada aos fatos das condições de secagem e das espécies de hortelã utilizadas serem diferentes em cada caso.

Em todos os ensaios, a variação da cor das hastes (Figura 5a) apresentou tendência de aumento até $6 \mathrm{~h}$ de processo e, a partir de então, variou pouco. Já para folhas (Figura 5b) a variação foi relativamente pequena durante todo o processo. Tanto para folhas quanto para hastes, os valores obtidos nos ensaios realizados a $80^{\circ} \mathrm{C}$ foram maiores que nos ensaios a $70{ }^{\circ} \mathrm{C}$, com diferenças de até $30,7 \%$ no fim do processo. Uma vez que a cor de plantas é dada pela presença de pigmentos (como a clorofila), e nutrientes (como nitrogênio, potássio, etc.), quanto à variação da cor, a secagem na temperatura de $70{ }^{\circ} \mathrm{C}$ é mais vantajosa, pois proporcionou menores alterações.
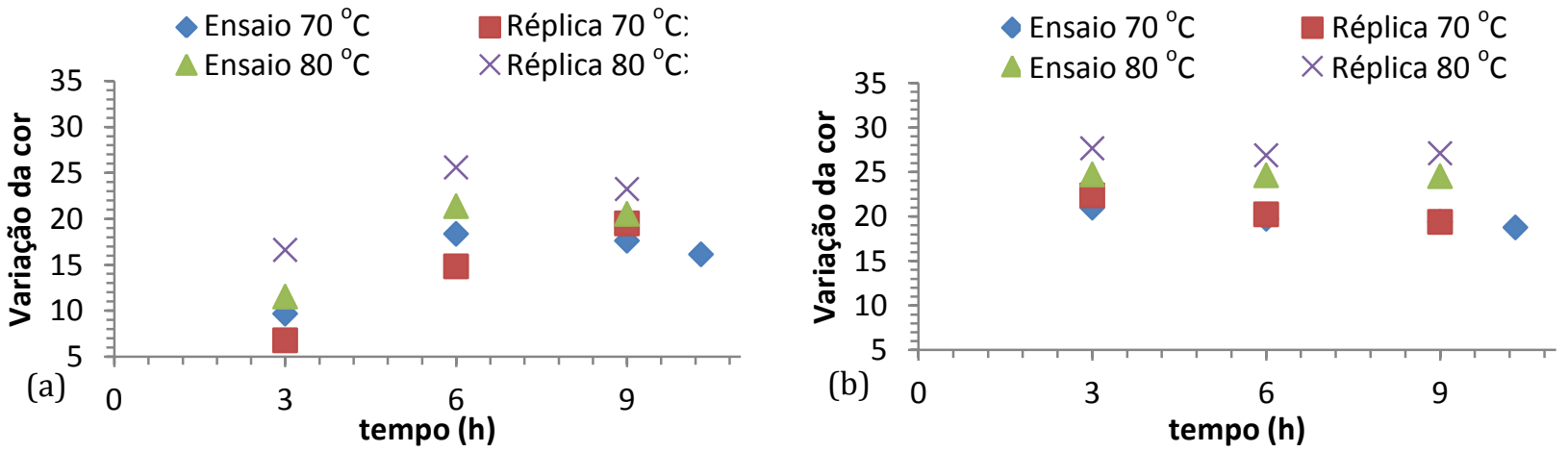

Figura 5 - Variação da cor de hastes (a) e folhas (b) em função do tempo de secagem.

Quanto à densidade bulk (Figura 6) os valores obtidos em todos os ensaios foram reprodutíveis entre ensaios e réplicas, e não foi observado efeito da temperatura nos resultados, já que as diferenças 
entre os experimentos realizados a 70 e $80{ }^{\circ} \mathrm{C}$, foram inferiores a 18,0\%. As densidades apresentaram uma tendência de aumento até $3 \mathrm{~h}$ de secagem, e a partir de então, uma redução com o tempo. Esse comportamento pode ser explicado pelo fato de no início da secagem (até $3 \mathrm{~h}$ ), ocorrer a maior redução no volume do material, uma vez que ele murcha e encolhe consideravelmente, enquanto que a redução mássica proporcionada pela retirada de água ainda é pequena, o que ocasiona um maior valor na razão entre a massa e o volume ocupado pelo material. Após $3 \mathrm{~h}$, a massa continua a diminuir com o tempo, mas a diminuição do volume é menor, ocasionando a diminuição da densidade bulk. Ainda, os valores finais obtidos foram próximos aos iniciais, o que indica que a redução do volume do material foi grande o suficiente para compensar a redução da massa devida à retirada da umidade.

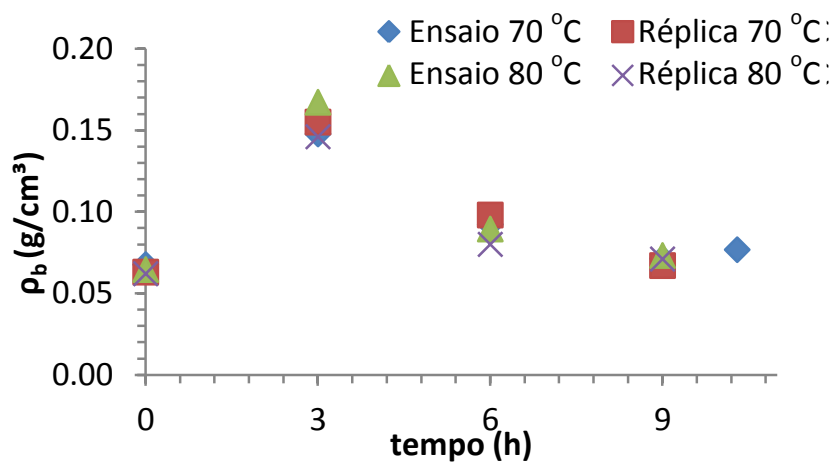

Figura 6 - Densidade bulk de folhas e hastes em função do tempo de secagem.

A grande redução no volume bulk do material pode ser observada nas fotos da Figura 7.

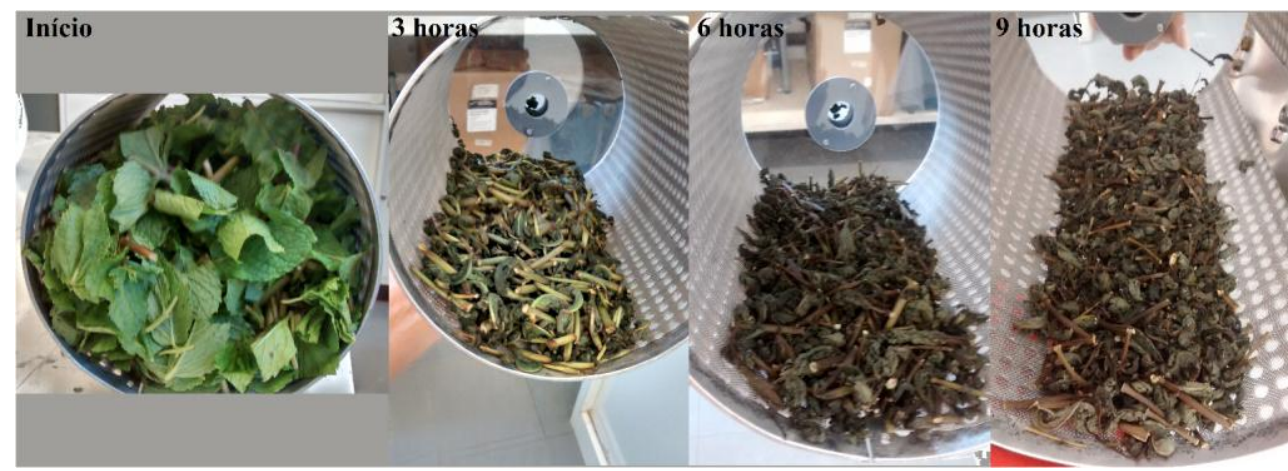

Figura 7 - Fotos da hortelã durante secagem a $70{ }^{\circ} \mathrm{C}$ em diferentes tempos de processo.

Nas fotos fica evidente o significativo encolhimento que a hortelã apresentou durante a secagem, principalmente nas 3 primeiras horas de processo. Esse encolhimento faz com que a resistência oferecida pelo meio ao escoamento varie muito neste período, afetando consequentemente, os processos de transferência de calor e massa. Além disto, o volume do secador só está sendo plenamente utilizado no início da secagem. Mesmo com a baixa velocidade de escoamento do ar no interior do cesto, é possível observar na Figura 7 que a secagem foi uniforme. O padrão ilustrado na figura foi observado para todos os experimentos, e com $9 \mathrm{~h}$ de secagem a umidade das folhas foi reduzida a valores finais de $9,55 \%$ em média, e das hastes a valores de $8,28 \%$, em média. 


\section{CONCLUSÕES}

Com base nos resultados, conclui-se que o secador do tipo cesto rotativo nas condições utilizadas, foi adequado para a secagem de hortelã-comum, promovendo boa movimentação do material e secagem homogênea. A densidade bulk do material sofreu pouca alteração se comparados os valores no início e final da secagem, sendo que o material encolheu significativamente com a redução da umidade. Para ambas as temperaturas do ar de secagem avaliadas $\left(70\right.$ e $\left.80{ }^{\circ} \mathrm{C}\right)$, não foram observadas diferenças significativas nas taxas de redução de umidade de folhas e hastes, entretanto, a utilização da temperatura de $70{ }^{\circ} \mathrm{C}$ é mais vantajosa para a secagem da hortelã, já que a cor do material foi melhor preservada nesta temperatura. Observou-se ainda que ao final da secagem as folhas apresentam umidade ligeiramente superior à das hastes. Este ainda é um estudo preliminar sobre o desempenho deste secador e são necessários estudos adicionais para avaliar a influência de outras variáveis do processo (como velocidade do ar, velocidade de rotação do cesto e massa do material) na secagem e também no teor e composição do óleo essencial. Além disto, precisam ser investigados as condições de escoamento, temperatura e movimentação das folhas no interior do cesto para futura modelagem da secagem.

\section{AGRADECIMENTOS}

Ao CNPq pelo auxílio financeiro.

\section{REFERÊNCIAS}

BLANCO, M. C. S. G.; MING, L. C.; MARQUES, M. O. M.; BOVI, O. A. Influência da temperatura de secagem no teor e na composição química do óleo essencial de menta. Hort. Bras. R., v. 18, 2000.

DIAS, R. A. L.; SOUZA, P. S.; ALSINA, O. L. S. Secagem e extração de taninos totais da hortelã (Mentha $x$ villosa Hudson). Agrar. R., v. 4, p. 123-133, 2011.

LIMA, R. A. B. Análise da secagem convectiva de folhas de manjericão (Ocimum basilicum L.). Tese (Doutorado em Engenharia Química). Universidade Federal de São Carlos, São Carlos, 2013.

MELO, E. C.; RADÜNZ, L. L.; MELO, R. C. A. Influência do processo de secagem na qualidade de plantas medicinais - Revisão. Eng. Agricul., v. 12, p. 307-315, 2004.

RADÜNZ, L. L.; MELO, E. C.; BARBOSA, L. C. A.; SANTOS, R. H. S.; BARBOSA, F. F.; MARTINAZZO, A. P. Influência da temperatura do ar de secagem no rendimento do óleo essencial de hortelã-comum (Mentha x villosa Huds). Eng. Agricult., v. 14, p. 250-257, 2006.

RIBEIRO, P. G. F.; DINIZ, R. C. Plantas aromáticas e medicinais: cultivo e utilização. Londrina: Editora IAPAR, 2008.

SANGWAN, A.; KAWATRA, A.; SEHGAL, S. Nutrient composition of mint powder prepared from various drying methods. Nutr. \& Food Sci., v. 42, p. 21-25, 2012.

TARHAN S.; TELCI, I.; TUNCAY, M. T.; POLATCI, H. Product quality and energy consumption when drying peppermint by rotary drum dryer. Ind. Crops and Prod., v. 32, p. 420-427, 2010. 